\title{
Acid Corrosive Injury in Patients with a History of Partial Gastrectomy: Outcome Analysis
}

\author{
Jia-Ming Chang ${ }^{a}$ Ming-Ho Wu ${ }^{a}$ Wu-Wei Lai ${ }^{a} \quad$ Mu-Yen Lin ${ }^{a} \quad$ Yueh-Feng Tsai ${ }^{b}$ \\ I-Ling Hsu ${ }^{a}$ Yi-Ting Yen ${ }^{a}$ Yau-Lin Tseng ${ }^{a}$ \\ ${ }^{a}$ Division of Thoracic Surgery, Department of Surgery, Medical College, National Cheng Kung University, and \\ ${ }^{b}$ Department of Surgery, Chi-Mei Medical Center, Tainan, Taiwan
}

\section{Key Words}

Acid corrosive injury $\cdot$ Pylorus $\cdot$ Post partial gastrectomy

\begin{abstract}
Background: Our purpose was to delineate the characteristics and outcome of acid-corrosive injury in patients with a history of gastric resection. Material and Methods: A total of 359 patients with a history of acid-corrosive injury were retrospectively reviewed. They were grouped based on past history with group 1 consisting of 8 patients with a history of gastric surgery (6 hemigastrectomies with Billroth II gastrojejunostomy, 2 partial gastrectomies with Billroth I gastroduodenostomy) and group 2 consisting of 351 patients without a history of previous gastric surgery. Clinical data, operative findings, treatment modalities and prognoses were compared. Results: Group 1 patients required significantly more emergency surgical interventions $(p=0.016)$ and more frequent resection of alimentary necrosis $(p=$ 0.007). In the operative findings of those undergoing emergency laparotomy, group 1 had a slightly higher incidence of total gastric necrosis with or without perforation $(p=$ $0.388)$, and a higher incidence of jejunal resection $(p=0.001)$. However, group 1 patients had a relatively lower operative mortality rate compared to group 2 patients $(p=0.640)$.
\end{abstract}

Conclusion: Acid-injured patients with a history of previous gastric surgery tended to have a higher incidence of mandatory emergency surgical exploration and resection of the alimentary tract. With early and prompt management, a good survival rate can still be anticipated.

Copyright $\odot 2007$ S. Karger AG, Basel

\section{Introduction}

In general, acid-corrosive injury causes the majority of injuries to the esophageal and stomach mucosae. Sequelae are more favorable in the stomach than in the esophagus, owing to the difference between coagulation injury (acid) as compared to liquefaction injury (alkaline) $[1,2]$.

The extent of the acid and its resultant damage is affected by several factors including the amount and concentration of the acid, swallowing speed, amount of residual gastric content (food or liquid), and contact time with the gastric mucosa [3]. However, other factors have been proposed to affect the spread of acid as well, such as immediate pyloric spasm shown in animal studies to prevent further downstreaming of acid into the duodenum and to cause its pooling in the stomach $[4,5]$.

\section{KARGER}

Fax +4161306 1234 E-Mail karger@karger.ch www.karger.com (c) 2007 S. Karger AG, Basel

0253-4886/07/0243-0202\$23.50/0

Accessible online at:

www.karger.com/dsu
Dr. Yau-Lin Tseng

Division of Thoracic Surgery, Department of Surgery

Medical College, National Cheng Kung University, 138, Sheng-Li Road

Tainan 704 (Taiwan)

Tel. +886 6235 3535, ext. 5181, Fax +886 6276 6676, E-Mail tsengyl@mail.ncku.edu.tw 
Whether ablation of pyloric function, due to either previous surgical resection or bypass surgery, affects the outcome of corrosive-injured patients has not been clinically evaluated. Estrera et al. [6] reported 2 cases of previous partial gastrectomy in a series of 62 caustic ingestions in 1985. The outcomes were both fatal. He proposed that normal esophagogastric anatomy that can change the chemical milieu, surface volume, and the emptying capacity of the stomach had been disrupted by the surgical procedures, leading to more serious injury after corrosive ingestion.

In this study, we compared the extent of injury, treatment variations, surgical procedures and outcomes in acid-injured patients with a history of previous gastric resection to those without, with different results than Estrera et al. [6]. We describe our experience in treating acid-injured patients with previous gastric surgery and discuss the role of the pylorus in acid corrosive injury.

\section{Material and Methods}

\section{Patient Selection}

From June 1988 to April 2004, the medical records of patients with a history of clinically evident acid corrosive injury who received management from the acute stage at our institution of the National Cheng-Kung University Hospital were reviewed retrospectively. They were divided into two groups based on their past history. Group 1 consisted of patients with a history of previous gastric resection before the acid-corrosive event, and group 2 of patients without any history of previous gastric surgery.

\section{General Management}

Management principles varied at three different stages of the corrosive injury, defined as: (1) acute stage: within the initial 7 days; (2) subacute stage: during days $8-21$; (3) chronic: beyond 21 days. Aggressive surgical intervention was meant to be life-saving in the acute stage, rather than required for management of complications or sequelae of the injury in subacute and chronic stages [7-9].

During the acute stage, serial physical exams assessed the presence of diffuse abdominal tenderness, muscle guarding or peritoneal signs. Laboratory evaluation consisted of complete blood count, leukocyte differential count, arterial blood gas, blood biochemistry, and CXR conducted in the emergency room (ER).

Indications for emergency surgery included shock status (systolic blood pressure $<90 \mathrm{~mm} \mathrm{Hg}$ ), shock index $\geq 1$ (pulse rate/systolic blood pressure $\geq 1$ ), generalized abdominal tenderness or frank peritonitis on physical examination, severe metabolic acidosis $(\mathrm{pH} \leq 7.0$, or base deficit $\leq-16 \mathrm{mmol} / \mathrm{l})$, pleural effusion, pyopneumothorax or pneumoperitoneum documented on radiography, and massive gastrointestinal bleeding [10]. Surgical procedures were based on the extension of the injury upon operative findings, varying from gastrostomy and jejunostomy in patients without full-thickness necrosis to total gastrectomy and transhi- atal esophagectomy, with or without duodenectomy, partial jejunectomy with concomitant cervical esophagostomy and jejunostomy in widespread full-thickness injury, or frank perforation of hollow organs necessitating extensive resection. In extreme cases, associated injuries of intra-abdominal organs such as the diaphragm, spleen, colon, gallbladder, pancreas or liver occurred and further resection was required.

Conservative treatment was initiated once no indications for emergency operation were met, which included nil per os (NPO) with decompression of the alimentary tract via nasogastric (NG) tube, parental nutrition support, correction of acid-base and electrolyte imbalances, and broad-spectrum antibiotics. Aluminum and magnesium oral suspension along with sucralfate (sucrose octakis (hydrogen sulfate) aluminum) via NG tube or oral route were initiated a day or two after the initial injury if oral intake could be resumed, or an intravenous $\mathrm{H} 2$ blocker in case of dysphagia or gastrointestinal bleeding was administered. In addition, routine esophagogastroduodenoscopic evaluation of the degree of corrosive burns were conducted within $48 \mathrm{~h}$ as a prognostic indicator and graded according to previous publications $[1,2]$.

\section{Statistical Analysis}

Clinical data including patient age, sex and time interval from initial injury to surgery, arterial blood gas, shock status, presence or absence of aspiration, surgical intervention required, intra-operative findings, the extension of the injury, surgical procedures, and outcomes were analyzed and compared between the groups. Continuous data were presented as mean \pm SEM and the differences between groups were analyzed using Student's t test statistics; $\chi^{2}$ statistics were utilized for the analysis of noncontinuous data. The Cox logistic regression model was used for univariate and multivariate outcome predictor analyses. All statistical tests were two-sided and $\mathrm{p}<0.05$ was considered statistically significant.

\section{Results}

There were a total of 359 patients managed after acidcorrosive injury from the acute stage at our institution with available medical data for analysis. All patients had ingested liquid forms of hydrochloric acid. However, the amount of ingested acid was quite unreliable by retrospective historic review and was hence excluded from analysis. The mean duration from initial injury to emergency room was $2.91 \pm 0.24 \mathrm{~h}$.

Group 1 consisted of 8 patients (8/359,2.2\%), 5 males and 3 females. Their ages ranged from 25 to 62 years with an average of 47.6 years. The clinical information, surgical procedures and outcomes for these 8 patients are summarized in table 1 . All of the 8 patients distributed evenly through the time-frame of 16 years (4 patients in the first 8 years and the other 4 in the last 8 years) and were treated by four different surgeons following our treatment guidelines as above. 
Table 1. Cumulative patients of acid-corrosive injury with previous gastric resections

\begin{tabular}{|c|c|c|c|c|c|}
\hline $\begin{array}{l}\mathrm{Pa}- \\
\text { tient }\end{array}$ & $\begin{array}{l}\text { Cause of previous } \\
\text { gastric resection }\end{array}$ & $\begin{array}{l}\text { Previous gastric } \\
\text { resection }\end{array}$ & Acute stage operations & Complications & Outcome \\
\hline 1 & UGI bleeding & $\begin{array}{l}\text { hemi-gastrectomy } \\
+ \text { BII anastomosis }\end{array}$ & $\begin{array}{l}\text { EG + extensive small bowel } \\
\text { resection + splenectomy }\end{array}$ & $\begin{array}{l}\text { sepsis, pneumonia with ARDS, } \\
\text { short bowel syndrome }\end{array}$ & dead \\
\hline 2 & UGI bleeding & $\begin{array}{l}\text { hemi-gastrectomy } \\
+ \text { BII anastomosis }\end{array}$ & $\mathrm{EG}+$ jejunal resection $25 \mathrm{~cm}$ & $\begin{array}{l}\text { 1. empyema with pyopericardium/ } \\
\text { decortication with pericardial window in D14 } \\
\text { 2. leakage of jejunojejunostomy/repair in D32 }\end{array}$ & $\begin{array}{l}\text { well but no } \\
\text { reconstruction }\end{array}$ \\
\hline 3 & unknown & $\begin{array}{l}\text { hemi-gastrectomy } \\
+ \text { BII anastomosis }\end{array}$ & conservative & & well \\
\hline 4 & $\begin{array}{l}\text { previous } \\
\text { corrosive injury }\end{array}$ & $\begin{array}{l}\text { partial gastrectomy } \\
+\mathrm{BI} \text { anastomosis }\end{array}$ & conservative & UGI bleeding & $\begin{array}{l}\text { delayed EG + T-Colon } \\
\text { reconstruction on D19 }\end{array}$ \\
\hline 5 & PPU & $\begin{array}{l}\text { hemi-gastrectomy } \\
+ \text { BII anastomosis }\end{array}$ & $\mathrm{EG}+$ jejunal resection $10 \mathrm{~cm}$ & & $\begin{array}{l}\text { ileocolon } \\
\text { reconstruction }\end{array}$ \\
\hline 6 & unknown & $\begin{array}{l}\text { hemi-gastrectomy } \\
+ \text { BII anastomosis }\end{array}$ & Conservative & & no sequela \\
\hline 7 & PPU & $\begin{array}{l}\text { hemi-gastrectomy } \\
+ \text { BII anastomosis }\end{array}$ & $\begin{array}{l}\text { EG + extensive small bowel } \\
\text { resection } 120 \mathrm{~cm}+\text { splenectomy }\end{array}$ & wound infection/debridement in D22 & colon reconstruction \\
\hline 8 & $\begin{array}{l}\text { previous } \\
\text { corrosive injury }\end{array}$ & $\begin{array}{l}\text { partial gastrectomy } \\
+\mathrm{BI} \text { anastomosis }\end{array}$ & $\begin{array}{l}\mathrm{EG}+\text { duodenectomy + parital } \\
\text { jejunectomy } 5 \mathrm{~cm}\end{array}$ & & $\begin{array}{l}\text { ileocolon } \\
\text { reconstruction }\end{array}$ \\
\hline
\end{tabular}

UGI = Upper gastrointestinal; PPU = perforated peptic ulcer; BI = Billroth I gastroduodenostomy; BII = Billroth II gastrojejunsotomy; EG = esophagogastrectomy.

Table 2. Comparison of clinical variables of overall 359 patients of caustic ingestions grouped by history of previous partial gastrectomy

\begin{tabular}{lccc}
\hline & Group 1 $(\mathrm{n}=8)$ & Group 2 $(\mathrm{n}=351)$ & p value \\
\hline Gender $(\mathrm{M} / \mathrm{F})$ & $5 / 3$ & $112 / 239$ & 0.119 \\
Age & $47.6 \pm 4.5$ & $42.4 \pm 0.9$ & 0.377 \\
White count, $\times 10^{3} / \mu \mathrm{l}$ & $19.4 \pm 2.9$ & $14.3 \pm 0.4$ & 0.831 \\
Platelet, $\times 10^{3} / \mu \mathrm{l}$ & $269.9 \pm 24.6$ & $221.1 \pm 4.8$ & 0.690 \\
Arterial blood gas & & & \\
$\quad \mathrm{pH}$ & $7.28 \pm 0.03$ & $7.32 \pm 0.01$ & 0.339 \\
$\quad$ Base deficit, mEq/1 & $11.24 \pm 2.32$ & $7.65 \pm 0.33$ & 0.085 \\
Shock index $\geq 1$ & $1(12.5 \%)$ & $17(4.8 \%)$ & 0.341 \\
Aspiration pneumonia & $0(0 \%)$ & $19(5.4 \%)$ & 1.000 \\
Emergency laparotomy & $5(62.5 \%)$ & $75(21.4 \%)$ & $0.016^{*}$ \\
Resection of alimentary tract & $5(62.5 \%)$ & $62(17.7 \%)$ & $0.007^{*}$ \\
Overall mortality & $1(12.5 \%)$ & $52(14.8 \%)$ & 1.000 \\
\hline
\end{tabular}

* Statistically significant.
Comparisons of clinical variables including intra-operative findings, procedures, and outcomes between group 1 and group 2 are demonstrated in table 2. Group 1 patients had a significantly higher incidence of requiring emergency surgery and resection of alimentary tracts $(5 / 8(62.5 \%)$ vs. $75 / 351(21.4 \%) \mathrm{p}=0.016,5 / 8$ (62.5\%) vs. $62 / 351(17.7 \%), \mathrm{p}=0.007)$.
The clinical variables, operative findings, procedures and surgical outcomes of patients requiring emergency surgery in these two groups are outlined in table 3 . The mean platelet count of group 1 patients was significantly higher than that of group 2 patients $(297 \pm 29.9$ to 162.36 $\left.\pm 8.87 \times 10^{3} / \mu \mathrm{l}, \mathrm{p}=0.000\right)$. During operation, total full-thickness necrosis of paper-thin wall of stomach 
Table 3. Clinical variables, operative findings, procedures, and surgical outcome of the acid injured patients requiring emergency surgery

\begin{tabular}{|c|c|c|c|}
\hline & Group $1(\mathrm{n}=5)$ & Group $2(n=75)$ & $\mathrm{p}$ value \\
\hline White count, $\times 10^{3} / \mu \mathrm{l}$ & $22.6 \pm 3.9$ & $17.3 \pm 9.8$ & 0.166 \\
\hline Platelet count, $\times 10^{3} / \mu \mathrm{l}$ & $297.0 \pm 29.9$ & $162.4 \pm 8.9$ & $0.000^{*}$ \\
\hline \multicolumn{4}{|l|}{ Arterial blood gas } \\
\hline $\mathrm{pH}$ & $7.26 \pm 0.05$ & $7.20 \pm 0.01$ & 0.265 \\
\hline Base deficit, mEq/l & $-12.46 \pm 3.41$ & $-13.58 \pm 0.61$ & 0.648 \\
\hline Duration from injury to operation, $\mathrm{h}$ & $15.1 \pm 19.3$ & $13.3 \pm 20.4$ & 0.846 \\
\hline \multicolumn{4}{|l|}{ Intra-operative findings } \\
\hline Esophageal perforation & $1(20 \%)$ & $0(0 \%)$ & 0.062 \\
\hline Gastric total necrosis or perforation & $4(80 \%)$ & $42(56 \%)$ & 0.388 \\
\hline \multicolumn{4}{|l|}{ Operative procedures } \\
\hline Esophagogastrectomy & $5(100 \%)$ & $63(84 \%)$ & 1.000 \\
\hline Duodenal resection & $1(20 \%)$ & $31(41.3 \%)$ & 0.643 \\
\hline Jejunal resection & $5(100 \%)$ & $28(37.3 \%)$ & $0.001^{*}$ \\
\hline $\begin{array}{l}\text { Associated resection required other } \\
\text { than alimentary tract }\end{array}$ & $2(40 \%)$ & $16(21.3 \%)$ & 0.313 \\
\hline Surgical mortality & $1(20 \%)$ & $35(46.7 \%)$ & 0.372 \\
\hline
\end{tabular}

* Statistically significant.
Table 4. Multivariate logistic regression analysis of risk factors for mortality among overall patients with corrosive injury $(n=359)$

\begin{tabular}{llrl}
\hline & Odds ratio & $95 \%$ CI & p value \\
\hline History of partial gastrectomy & 0.123 & $0.00-1.76$ & 0.123 \\
Platelet count, $\times 10^{3} / \mu \mathrm{l}$ & 1.007 & $1-1.01$ & 0.053 \\
$\begin{array}{l}\text { Base deficit, } \mathrm{mEq} / \mathrm{l} \\
\begin{array}{l}\text { Gastric total necrosis or } \\
\quad \text { perforation }\end{array}\end{array}$ & 1.149 & $1.06-1.24$ & $0.001^{*}$ \\
\begin{tabular}{l} 
Jejunal resection required \\
\hline
\end{tabular} & 3.616 & $1.31-10.00$ & $0.013^{*}$ \\
\hline
\end{tabular}

* Statistically significant.

with impending perforation or gastric wall perforation with turbid ascites was observed in 4 patients in group 1 compared to 42 patients in group $2(80-56 \%, \mathrm{p}=0.388)$. There was only one case of esophageal perforation (patient 2$)$ in group 1 and none in group 2 patients $(20-0 \%$, $\mathrm{p}=0.062)$. This 1 patient was referred to our hospital $48 \mathrm{~h}$ after acid injury with the presentation of pyopneumothorax. Clinical variables listed in table 3 were also tested as risk factors for mortality among overall cases using the Cox logistic regression model and only those entering multivariate analysis $(\mathrm{p}<0.05$ in univariate analysis) were shown in table 4 . Significant independent negative predictors included base deficit, total gastric necrosis or perforation, and jejunal extension requiring re- section. Platelet count reached borderline significance $(\mathrm{p}=0.053)$.

One surgical mortality occurred in group 1 patients (patient 1) who suffered from extensive corrosive injury and underwent esophagogastrectomy with extensive small bowel resection; she died in sepsis and acute respiratory distress syndrome on day 43. Before her referral to our hospital, this patient underwent gastric lavage. All of the remaining group 1 patients received long-term follow-up except for patient 6 , duration ranging from 8 to 81 months (mean 42.6 months). Three of the five group 1 patients who underwent emergency operation received further esophageal reconstruction utilizing ileocolon grafts and left-sided colon graft interposition after 4-6 months (mean 5 months). The follow-up data of the whole series of 359 patients have been presented thoroughly in our previous publications $[2,7,10,11]$ and therefore omitted from tautologous descriptions.

\section{Discussion}

Although the occurrence of acid injury in patients with history of gastrectomy (groupl) was rare, these patients did have several distinguishing features. First, the incidence of requiring emergency surgery for resection of the alimentary tract was significantly higher in group 1 . This is consistent with Estrera's proposal that previous gastrectomy may alter the normal function of the stomach and 
make these patients less tolerant of corrosive agents. Decreased gastric volume and ablation of normal pyloric function causing rapid transit of acid into the small bowel, which is less resistant to corrosive agents, appears to be the major factors leading to more surgical intervention. The possibility remains that most of these patients ingested large amount of acid, but this seems unlikely.

The second point concerns the findings of patients requiring emergency surgery. In 1938, Testa [12] demonstrated that pyloric spasm might cause retention of corrosives and cause maximal damage when these agents were pooled in the stomach [13]. The incidence of near total necrosis of stomach with or without gastric perforation was expected to be more frequent in severely corrosive-injured patients who had a patent pylorus. However, on the contrary, our study found a slightly increased tendency in group 1, with all except 1 patient having total full-thickness gastric necrosis. This could also possibly be attributed to decreased gastric volume, which could tolerate less acid corrosion and be easily destroyed. Severe acid injury often causes gastric perforation with injury of surrounding organs by means of corrosive flooding into the abdomen cavity, or through thermal injury transmission via direct contact. Our analysis showed that group 1 patients seemed to have a higher incidence of associated organ resection. However, we found that gastric perforation in group 1 patients was always confined to the fundic area and rarely caused flooding of the corrosives into the whole abdomen. The only concomitantly resected organ in group 1 patients was the spleen. Splenic resection in these 2 patients was partially due to iatrogenic injury in addition to direct acid injury because of severe abdominal adhesions following previous gastric surgery. From this point of view, it seems that pyloric spasm has a detrimental effect on severe acid injury, raising the possibility of adjacent damage. However, immediate reflux pyloric spasm, induced by irritant contact with corrosives, might prevent further extension beyond the duodenum and jejunum, which would otherwise greatly increase the mortality rate, thereby having a protective effect on severe acid injury. Without a pylorus, jejunal injury was inevitable and always required partial resection in the patients requiring emergency surgery. However, the injury pattern of jejunum was always patchy whole layer necrosis instead of frank perforation. This appears to be related to rapid transit of corrosives into the jejunum. Because group 1 patients had gastric perforation, which usually was not widespread, and tended to have more intraluminal injury from esophagus to jejunum, frank rebounding peritoneal signs might not be present. General abdominal tenderness due to inflammatory ascites or lower abdominal tenderness because of whole layer necrosis of the jejunum might be the only presentation. Physicians should keep in mind that these patients would have a higher risk for mandatory emergency surgical exploration.

It has been found that acids were propelled rapidly through the esophagus, causing superficial damage, then further descended into the stomach with more extensive injury [4, 14]. Although Horvath et al. [15] reported 2 cases of esophageal perforation after acid injury, we did not encounter any esophageal perforation due to acid injury in the patients without history of gastric surgery. The only esophageal perforation in this series occurred in patient 2 with previous subtotal gastrectomy with BII anastomosis. We believe that previous gastric surgery might interfere with the phrenicoesopahgeal ligment, crural fibers of the diaphragm change the angle of His and shorten the intra-abdominal esophageal length; all of these could disturb the normal anatomy of the lower esophageal sphincter and gastroesophageal junction, making the lower esophagus further injured through possible reflux of the causatives [16]. The operative findings of resected lower esophagus of group 1 patients all showed whole-layer necrosis. This supports our theory and is also the reason why we suggest routine concomitant resection of the esophagus rather than just gastrectomy and jejunectomy in group 1 type patients.

The third main finding of this study is that, in contrast to the report from Estrera et al. [6], group 1 patients undergoing emergency surgery tended to have a more favorable outcome than group 2 patients, though not statistically significantly. The phenomenon of consumption coagulopathy caused by necrosis of the alimentary injury and perifocal vascular thrombosis has been considered by some authors an indicator of severity as well as metabolic acidosis [17]. The mean platelet count in group 1 was significantly higher than group 2 and also a borderline negative predictor in overall cases with corrosive injury. This might imply that group 1 patients had less injury severity than group 2 patients. Two important factors might explain this result. The first is lesser tolerance of group 1 patients for large amounts of acid agents because of decreased gastric volume; along with the rapid transit of agents, their injuries were often limited to the gastrointestinal tract lumen and surrounding organs less injured by acid. The second factor is lesser duodenal involvement in group 1 patients. The acid was found to cause jejunal injury only on efferent loop in patients with gastrectomy and BII gastrojejunstomy, which constituted the majority of the group 1 patients. The duodenum and 
afferent loop of the jejunum were spared. Duodenal injury remains the critical point in extensive surgery of acid-corrosive injury because inevitably, associated injury of the pancreas and common bile duct makes the operation technically demanding and often complicates the subsequent clinical course, for example leakage and further chemical peritonitis, intra-abdominal abscess, sepsis and other respiratory and abdominal complications [7, $11,18]$. Without duodenal involvement, acid-injured patients usually have favorable surgical results. This was proved in our univariate logistic analysis $(\mathrm{p}<0.05)$ but it failed to correlate significantly with prognosis in multivariate analysis due to interaction with other factors. Because of the limited case number of our series and the composition of BI and BII anastomosis, this issue deserves further investigation.

The only mortality in group 1 was associated with gastric lavage before referral to our hospital. Gastric lavage has been suggested to be a factor causing aspiration pneumonia [10]. However, this occurred in patients with nor- mal pylorus function in which pyloric spasm could prevent the extension of corrosive agents beyond duodenum and might cause regurgitation or vomiting leading to aspiration pneumonia. In those with ablated pyloric function, lavage would rapidly push the corrosives into the duodenum and/or jejunum and cause more extensive injury as in patient 1 . Therefore, gastric lavage or neutralization should be avoided in corrosive-injured patients.

\section{Conclusion}

The pylorus plays a distinct role in acid corrosive injury. Its ablation by previous surgery increased the need for acid-injured patients to undergo surgical resection of alimentary tracts. Surgeons should be more alert to acidinjured patients with history of previous gastric surgery. With early and prompt surgical intervention, a good survival rate can be anticipated.

\section{References}

1 Zargar SA, Kochhar R, Nagi B, Mehta S, Mehta SK: Ingestion of corrosive acids. Spectrum of injury to upper gastrointestinal tract and natural history. Gastroenterology 1989; 97:702-707.

-2 Tseng YL, Wu MH, Lin MY, et al: Early surgical correction for isolated gastric stricture following acid corrosive injury. Dig Surg 2002;19:276-280.

>3 Allen RE, Thoshinsky MJ, Stallone RJ, Hunt TK: Corrosive injuries of the stomach. Arch Surg 1970;100:409-413.

$\checkmark 4$ Citron BP, Pincus IJ, Geokas MC, et al: Chemical trauma of the esophagus and stomach. Surg Clin North Am 1968;48: 1303.

$\checkmark 5$ Chong GC, Beahrs OH, Payne WS: Management of corrosive gastritis due to ingested acid. Mayo Clin Proc 1974;49:861-865.

$\checkmark 6$ Estrera A, Taylor W, Mills LJ, Platt MR: Corrosive burns of the esophagus and stomach: a recommendation for an aggressive surgical approach. Ann Thorac Surg 1986;41:276283.
7 Wu MH, Lai WW: Surgical management of extensive corrosive injuries of the alimentary tract. Surg Gynecol Obstet 1993;177:1216.

$\checkmark 8$ Cattan P, Munoz-Bongrand N, Berney T, et al: Extensive abdominal surgery after caustic ingestion. Ann Surg 2000;231:519-523.

-9 Sarfati E, Gossot D, Assens P, et al: Management of caustic ingestions in adults. Br J Surg 1987;74:146-181.

10 Tseng YL, Wu MH, Lin MY, Lai WW: Outcome of acid ingestion related aspiration pneumonia. Eur J Cardiothorac Surg 2002; 1: 638-643.

11 Wu MH, Lai WW, Hwang TL, et al: Surgical results of corrosive injuries involving esophagus to jejunum. Hepatogastroenterology 1996:43:846-850.

12 Testa GF: Contributo radiologico spirimentale allo studio delle lesions esofagee e gastriche nelle causticazione de alkali. Radiol Med 1938;25:17-25.
13 Sculengerg CAR: Corrosive stricture of stomach: without involvement of the esophagus. Lancet 1941;ii:367-368.

14 Wright JE, Hennessy EJ: Pyloric obstruction due to ingestion of corrosives. Med J Aust 1972;72:761-764.

15 Horvath OP, Olah T, Zentai G: Emergency esophagogastrectomy for treatment of hydrochloric acid injury. Ann Thorac Surg 1991;52:98-101.

16 Paterson WG: The normal antireflux mechanism. Chest Surg Clin N Am 2001:11:473483.

17 Lambert H, Renaud D, Weber M, Bauer P: Current treatment of poisoning by ingestion of caustic substances. J Toxicol Clin Exp 1992;12:11-26.

18 Jeng LB, Chen HY, Chen SC, et al: Upper gastrointestinal tract ablation for patients with extensive injury after ingestion of strong acid. Arch Surg 1994:129:1086-1090. 